\title{
EKSTRAKSI PEKTIN DARI KULIT BUAH PISANG KEPOK (Musa paradisiaca)
}

\author{
Farida Hanum, Martha Angelina Tarigan, Irza Menka Deviliany Kaban \\ Departemen Teknik Kimia, Fakultas Teknik, Universitas Sumatera Utara, \\ Jl. Almamater Kampus USU Medan 20155, Indonesia \\ Email : ida_hanum78@yahoo.co.id
}

\begin{abstract}
Abstrak
Pektin merupakan polimer dari asam D-galakturonat yang dihubungkan oleh ikatan $\beta$-1,4 glikosidik. Senyawa pektin banyak digunakan dalam industri farmasi, makanan dan minuman. Penelitian ini bertujuan untuk memanfaatkan limbah kulit buah pisang kepok (Musa paradisiaca) sebagai sumber pektin. Penelitian ini dilakukan dengan metode ekstraksi menggunakan pelarut asam kemudian ditambahkan etanol ke dalam filtrat untuk mengendapkan pektin dan proses terakhir dilakukan pengeringan untuk mendapatkan pektin kering. Variabel tetap yang digunakan dalam penelitian ini adalah berat kulit buah pisang kepok 10 gram, kadar air awal bahan 10\%, dan pelarut asam klorida ( $\mathrm{HCl}$ ). Sedangkan variabel berubahnya adalah $\mathrm{pH}$ ekstraksi 1; 1,5; 2; waktu ekstraksi 70, 80, 90, 100 menit, dan temperatur ekstraksi $80^{\circ} \mathrm{C}, 90{ }^{\circ} \mathrm{C}$. Hasil penelitian menunjukkan bahwa rendemen hasil ekstraksi terbaik dapat diperoleh pada temperatur $90^{\circ} \mathrm{C}, \mathrm{pH} \mathrm{1,5}$ selama 80 menit dengan kadar air $11,88 \%$, kadar abu 0,98\%, dan kadar metoksil 3,72\%.
\end{abstract}

Kata kunci : ekstraksi, pengeringan, pektin, rendemen, kadar metoksil

\begin{abstract}
Pectin are polymer of D-galacturonic acid connected by $\beta-1,4$ glucosidic. Pectin are widely used in pharmaceutical, food and beverage industries. This research was expected to took advantage of banana peels (Musa paradisiaca) by producing pectin. The research used an extraction method by using acid solvent in additional to ethanol to form the sediment of pectin and the last step is drying in order to get dry pectin. The fixed variables which were used in this research were 10 grams banana peels, $10 \%$ water content of sample, and chloride acid solvent. Extraction process was carried out by $\mathrm{pH} 1 ; 1,5 ; 2$; extraction time of $70,80,90,100$ minute, and temperature of $80^{\circ} \mathrm{C}, 90^{\circ} \mathrm{C}$. The results showed that the highest yield of pectin extraction was obtained at temperature of $80^{\circ} \mathrm{C}, \mathrm{pH} 1,5$ during 80 minute with $11,88 \%$ water content, $0,98 \%$ ash content, and 3,72\% the methoxyl content.
\end{abstract}

Keywords : extraction, drying, pectin, yield, methoxyl content

\section{Pendahuluan}

Pisang adalah buah-buahan tropis yang paling banyak dihasilkan dan dimanfaatkan oleh masyarakat Indonesia. Produksi buah pisang menduduki peringkat pertama hasil pertanian di Indonesia. Pemanfaatan buah pisang yang besar untuk berbagai jenis makanan, akan menghasilkan limbah berupa kulit pisang. Bobot kulit pisang mencapai $40 \%$ dari buahnya [6]. Dengan demikian kulit pisang menghasilkan limbah dengan volume yang besar [9].

Buah pisang mengandung pektin dalam konsentrasi tinggi. Kandungan pektin pada kulit pisang berkisar antara $0,9 \%$ dari berat kering. Pektin tersebut dapat diekstraksi dengan cara sederhana, biaya yang tidak mahal dan dapat diterapkan dalam skala kecil [7].

Hingga tahun 2011, seluruh pektin yang digunakan di industri-industri Indonesia adalah barang impor. Jumlah impor pektin cukup besar, yaitu lebih besar dari 100 ton per tahun dan harganya sangat mahal, membuat biaya impor pektin berdampak terhadap pengurangan devisa negara yang besar pula [2].

\section{Teori}

Pektin adalah polisakarida kompleks yang bersifat asam yang terdapat dalam jumlah bervariasi, terdistribusi secara luas dalam jaringan tanaman. Umumnya terdapat di dalam dinding sel primer. Khususnya di sela-sela antara selulosa dan hemiselulosa. Pektin juga berfungsi sebagai bahan perekat antara dinding sel yang satu dengan yang lainnya. Substansi pektin tersusun dari asam poligalakturonat, dimana gugus karboksil dari unit asam poligalakturonat dapat teresterifikasi sebagian dengan metanol [7].

Senyawa pektin adalah asam pektat, asam pektinat dan protopektin.

1. Asam Pektat

Asam pektat adalah senyawa asam galakturonat yang bersifat koloid dan pada dasarnya bebas dari kandungan metil ester [4].

2. Asam Pektinat

Asam pektinat adalah asam poligalakturonat yang bersifat koloid dan mengandung sejumlah metil ester. 
Pektin merupakan asam pektinat dengan kandungan metil ester dan derajat netralisasi yang berbeda-beda [4].

\section{Protopektin}

Protopektin adalah substansi pektat yang tidak larut dalam air, terdapat dalam tanaman, jika dipisahkan secara hidrolisis akan menghasilkan asam pektinat [10].

Senyawa asam pektinat atau pektin diberikan pada gambar 1 di bawah ini [7].
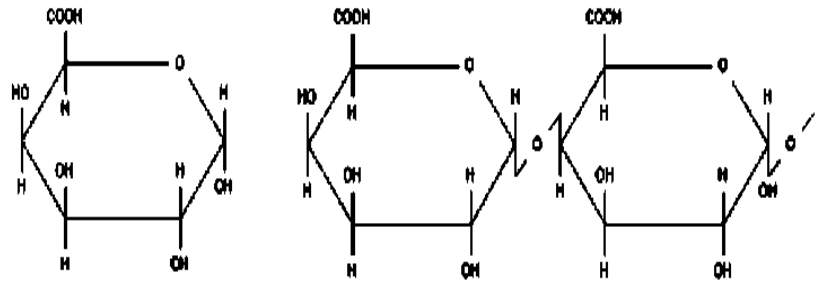

Asam $\alpha$ galakturonat

Polimer asam $\alpha$ galakturonat

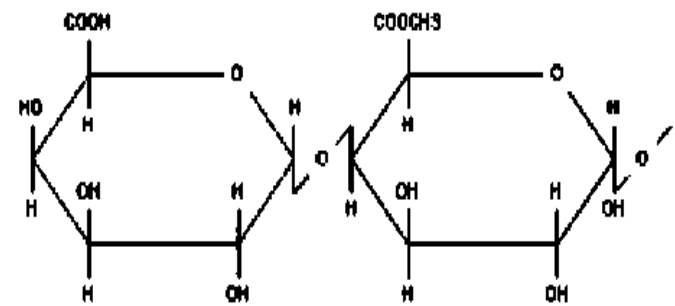

Polimer asam $\alpha$ galakturonat dimana sebagian gugus karboksilnya teresterifikasi dengan metil menjadi gugus metoksil

\section{Gambar 1. Senyawa Asam Pektinat atau Pektin}

Tabel 1. Standar Mutu Pektin Berdasarkan Standar Mutu International Pectin Producers Association [8]

\begin{tabular}{|l|l|}
\hline \multicolumn{1}{|c|}{ Faktor Mutu } & \multicolumn{1}{c|}{ Kandungan } \\
\hline Kekuatan gel & Min 150 grade \\
Kandungan metoksil : & $>7,12 \%$ \\
- Pektin metoksil tinggi & $2,5-7,12 \%$ \\
- Pektin bermetoksil rendah & Min 35\% \\
Kadar asam galakturonat & Maks $12 \%$ \\
Susut pengeringan (kadar air) & Maks $10 \%$ \\
Kadar abu & Maks $12 \%$ \\
Kadar air & \\
Derajat esterifikasi untuk : & Min $50 \%$ \\
- Pektin ester tinggi & Maks $50 \%$ \\
- Pektin ester rendah & $0,15-0,45 \%$ \\
Bilangan Asetil & $600-800 \mathrm{mg}$ \\
Berat Ekivalen & \\
\hline
\end{tabular}

\section{Metodologi Penelitian}

Bahan baku yang digunakan dalam penelitian ini adalah kulit buah pisang kepok dan bahan kimia berupa asam klrida $(\mathrm{HCl})$, air $\left(\mathrm{H}_{2} \mathrm{O}\right)$, etanol $\left(\mathrm{C}_{2} \mathrm{H}_{5} \mathrm{OH}\right)$, perak nitrat $\left(\mathrm{AgNO}_{3}\right)$, natrium hidroksida $(\mathrm{NaOH})$, natrium klorida $(\mathrm{NaCl})$, dan phenolptalein. Tahap awal adalah persiapan bahan baku dimana kulit buah pisang kepok dikeringkan di oven dan diukur kadar airnya $10 \%$.

Percobaan utama untuk mengetahui pengaruh temperatur, $\mathrm{pH}$, dan waktu ekstraksi terhadap rendemen, kadar air, kadar abu, dan kadar metoksil. Percobaan dilakukan dengan variasi temperatur 80 ${ }^{\circ} \mathrm{C}$ dan $90^{\circ} \mathrm{C}$, variasi $\mathrm{pH} 1 ; 1,5 ; 2$ dan variasi waktu ekstraksi 70, 80, 90, dan 100 menit. Rangkaian alat yang digunakan seperti gambar 2 .

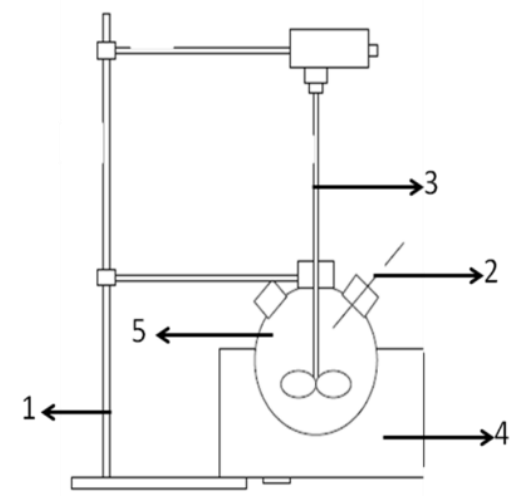

Keterangan :

1. Statif dan klem

2. Termometer

3. Stirrer

4. Heating mantle

5. Labu leher tiga

\section{Gambar 2. Rangkaian peralatan ekstraksi}

Bahan baku kemudian ditambahkan air sebanyak 35 kali dan diekstraksi di atas heating mantle dengan pengadukan. Campuran yang telah diekstrak disaring dengan menggunakan kertas saring untuk memisahkan filtrat dari ampasnya. Filtrat didinginkan kemudian dilakukan pengendapan pektin dengan menambahkan etanol yang telah diasamkan. Endapan pektin yang diperoleh kemudian dikeringkan dalam oven pada temperatur $40^{\circ} \mathrm{C}$ selama 8 jam. Pektin kering dianalisa kadar air, kadar abu, berat ekivalen, dan kadar metoksilnya. Kemudian hasil analisa dibandingkan dengan standar mutu pektin berdasarkan standar mutu International Pectin Producers Association (IPPA).

\section{Hasil}

Data hasil percobaan yang diperoleh dapat dilihat pada tabel 2 . 
Tabel 2. Data hasil percobaan

\begin{tabular}{|c|c|c|c|c|}
\hline $\mathrm{pH}$ & Suhu $\left({ }^{\circ} \mathrm{C}\right)$ & $\begin{array}{l}\text { Waktu } \\
\text { (menit) }\end{array}$ & $\begin{array}{c}\text { Massa Pektin } \\
\text { (gram) }\end{array}$ & $\begin{array}{c}\text { Kadar Metoksil } \\
(\%)\end{array}$ \\
\hline \multirow{8}{*}{1} & \multirow{4}{*}{80} & 70 & 3 & 2,48 \\
\hline & & 80 & 4,4 & 2,73 \\
\hline & & 90 & 4,26 & 2,85 \\
\hline & & 100 & 3,1 & 3,10 \\
\hline & \multirow{4}{*}{90} & 70 & 2,5 & 2,54 \\
\hline & & 80 & 4,2 & 2,98 \\
\hline & & 90 & 3,3 & 3,22 \\
\hline & & 100 & 2 & 3,41 \\
\hline \multirow{8}{*}{1,5} & \multirow{4}{*}{80} & 70 & 2 & 2,66 \\
\hline & & 80 & 4,68 & 3,04 \\
\hline & & 90 & 3,29 & 3,10 \\
\hline & & 100 & 2,5 & 3,35 \\
\hline & \multirow{4}{*}{90} & 70 & 4 & 2,91 \\
\hline & & 80 & 5,21 & 3,72 \\
\hline & & 90 & 3,77 & 3,41 \\
\hline & & 100 & 1,9 & 3,53 \\
\hline \multirow{8}{*}{2} & \multirow{4}{*}{80} & 70 & 1,5 & 3,10 \\
\hline & & 80 & 3,9 & 3,29 \\
\hline & & 90 & 3,4 & 3,46 \\
\hline & & 100 & 2,4 & 3,60 \\
\hline & \multirow{4}{*}{90} & 70 & 1,2 & 3,16 \\
\hline & & 80 & 4,5 & 3,35 \\
\hline & & 90 & 3,5 & 3,60 \\
\hline & & 100 & 2,5 & 3,66 \\
\hline
\end{tabular}

A. Pengaruh $\mathrm{pH}$ dan waktu ekstraksi terhadap rendemen pektin

Gambar 3 menunjukkan bahwa temperatur, $\mathrm{pH}$, dan waktu ekstraksi berpengaruh terhadap rendemen pektin hasil ekstraksi. Prinsip ekstraksi pektin adalah perombakan protopektin yang tidak larut menjadi pektin yang dapat larut. Ekstraksi pektin ini dapat dilakukan dengan hidrolisis asam atau enzimatis. Reaksi hidrolisis akan semakin cepat apabila konsentrasi asam semakin tinggi dan sebaliknya [12]. Suhu ekstraksi yang tinggi menyebabkan peningkatan energi kinetik larutan sehingga difusi pelarut ke dalam sel jaringan semakin meningkat pula. Hal ini berakibat terlepasnya pektin dari sel jaringan sehingga pektin yang dihasilkan semakin banyak. Semakin lama waktu dan semakin tinggi suhu ekstraksi, rendemen pektin yang dihasilkan semakin besar [11]. Tetapi pada waktu ekstraksi dinaikkan menjadi 90 menit, rendemen semakin sedikit karena pada waktu 90 menit tersebut sudah terjadi pemutusan ikatan glikosida dimana pektin yang terbentuk mengalami degradasi.

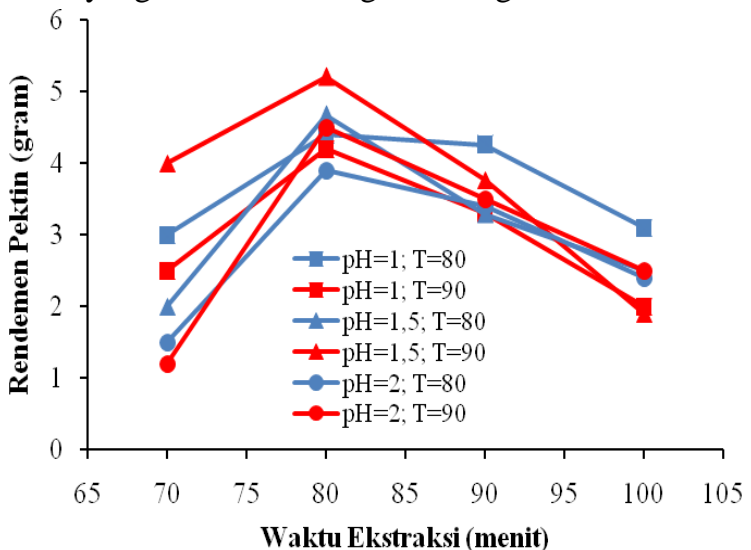

Gambar 3. Pengaruh pH dan waktu ekstraksi terhadap rendemen pektin

B. Pengaruh $\mathrm{pH}$ dan waktu ekstraksi terhadap kadar air pektin

Kadar air bahan berpengaruh terhadap masa simpan. Kadar air yang tinggi menyebabkan kerentanan terhadap aktivitas mikroba. Dalam upaya memperpanjang masa simpan pektin, dilakukan pengeringan pada oven suhu $40{ }^{\circ} \mathrm{C}$ selama 8 jam. Pengeringan pada suhu rendah bertujuan meminimalkan degradasi pektin [1].

Kadar air pektin yang dihasilkan berkisar antara 9,52-11,88\%. Batas maksimum nilai kadar air yang diizinkan yaitu 12\% [5]. Berdasarkan standar Food Chemical Codex (1996), semua perlakuan masih memenuhi standar dengan kadar air pektin di bawah $12 \%$. Kadar air yang dihasilkan dapat dipengaruhi oleh rendemen pektin. Semakin tinggi rendemen pektin, kadar air yang dihasilkan semakin tinggi pula [1].

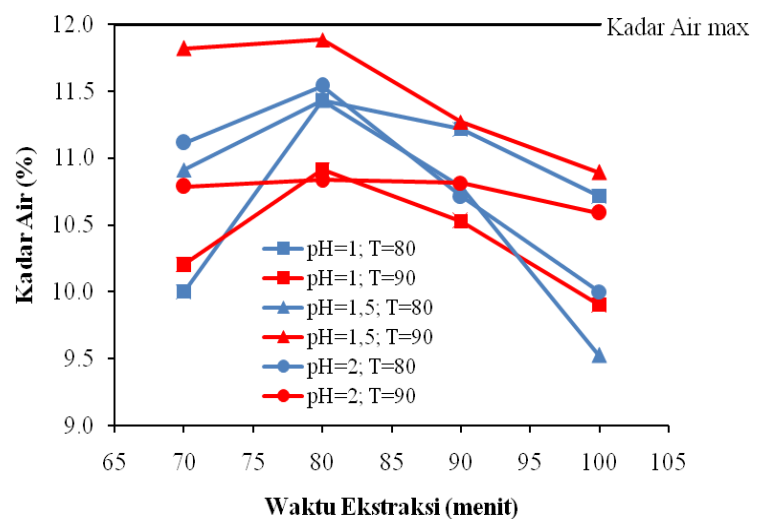

Gambar 4. Pengaruh pH dan waktu ekstraksi terhadap kadar air pektin 
C. Pengaruh $\mathrm{pH}$ dan waktu ekstraksi terhadap kadar abu pektin

Abu merupakan residu atau sisa pembakaran bahan organik yang berupa bahan anorganik. Kadar abu berpengaruh pada tingkat kemurnian pektin. Semakin tinggi tingkat kemurnian pektin, kadar abu dalam pektin semakin rendah [1]. Perlakuan dengan asam mengakibatkan terhidrolisisnya pektin dari ikatan kalsium dan magnesiumnya. Jadi apabila asam yang digunakan mempunyai $\mathrm{pH}$ tinggi maka kadar abunya tinggi. Pada hidrolisis dengan asam, ion-ion akan lepas dari substansi pektin. Semakin lama perlakuan dengan asam, ion-ion ini akan lebih banyak dilepaskan sehingga kadar abu semakin tinggi 13].

Hasil penelitian menunjukkan kadar abu pektin yang diperoleh berkisar antara 0,98-8\% yang sesuai dengan standar mutu kadar abu pektin yang ditetapkan IPPA (International Pectin Producers Association), yaitu maksimum 10\% sedangkan menurut Food Chemical Codex, kadar abu pektin yang diijinkan kurang dari $1 \%$.

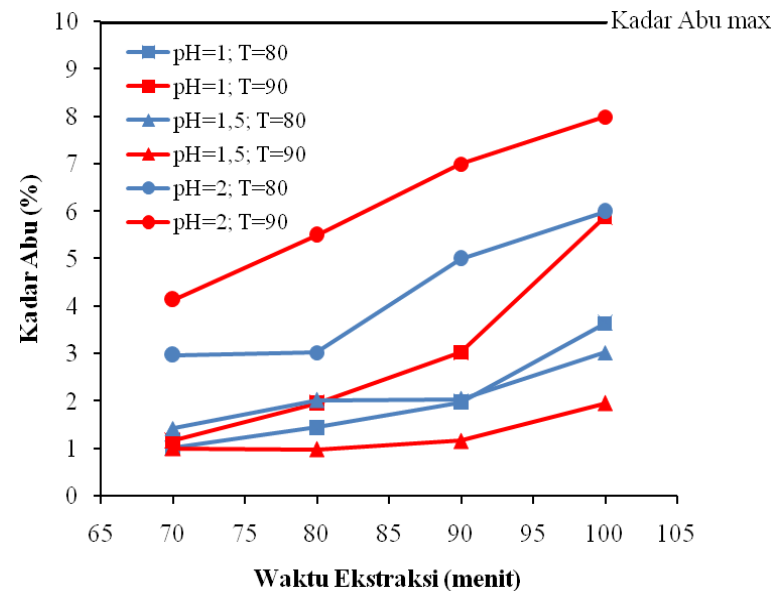

Gambar 5. Pengaruh pH dan waktu ekstraksi terhadap kadar abu pektin

D. Pengaruh $\mathrm{pH}$ dan waktu ekstraksi terhadap berat ekivalen pektin

Berat ekivalen merupakan ukuran terhadap kandungan gugus asam galakturonat bebas (tidak teresterifikasi) dalam rantai molekul pektin. Asam pektat murni merupakan zat pektat yang seluruhnya tersusun dari asam poligalakturonat yang bebas dari gugus metal ester atau tidak mengalami esterifikasi. Semakin rendah kadar pektin akan menyebabkan berat ekivalen semakin rendah [15].

Gambar di bawah menunjukkan adanya kecenderungan semakin tinggi suhu dan lamanya ekstraksi menghasilkan berat ekivalen semakin rendah. Pada penelitian ini berat ekivalen yang diperoleh dapat diterima, karena berdasarkan standar IPPA
(International Pectin Producers Association) berat ekivalen adalah 600-800 mg.

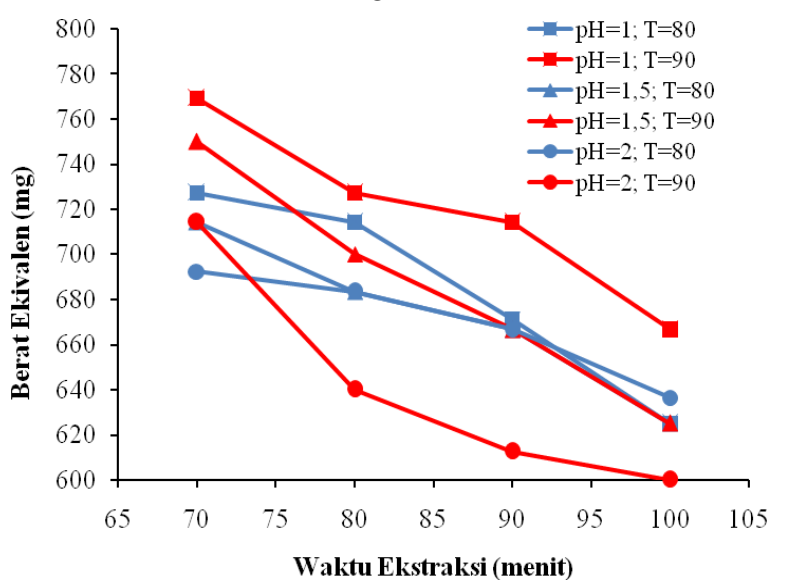

Gambar 6. Pengaruh pH dan waktu ekstraksi terhadap berat ekivalen pektin

E. Pengaruh $\mathrm{pH}$ dan waktu ekstraksi terhadap kadar metoksil pektin

Kadar metoksil didefinisikan sebagai jumlah mol etanol yang terdapat di dalam $100 \mathrm{~mol}$ asam galakturonat. Kadar metoksil pektin memiliki peranan penting dalam menentukan sifat fungsional larutan pektin dan dapat mempengaruhi struktur dan tekstur dari gel pektin [3].

Kadar metoksil pektin kulit pisang kepok dapat dilihat pada gambar di atas. Kadar metoksil pektin hasil ekstraksi berkisar antara 2,48-3,72\%. Menurut Hoejgaard (2004) berdasarkan jumlah kelompok esternya, jenis pektin yang dihasilkan dalam penelitian bermetoksil rendah karena mempunyai kelompok kadar metoksil kurang dari 7,12\% [14]. Hal ini lebih menguntungkan karena pektin bermetoksil rendah dapat langsung diproduksi tanpa melalui proses demetilasi.

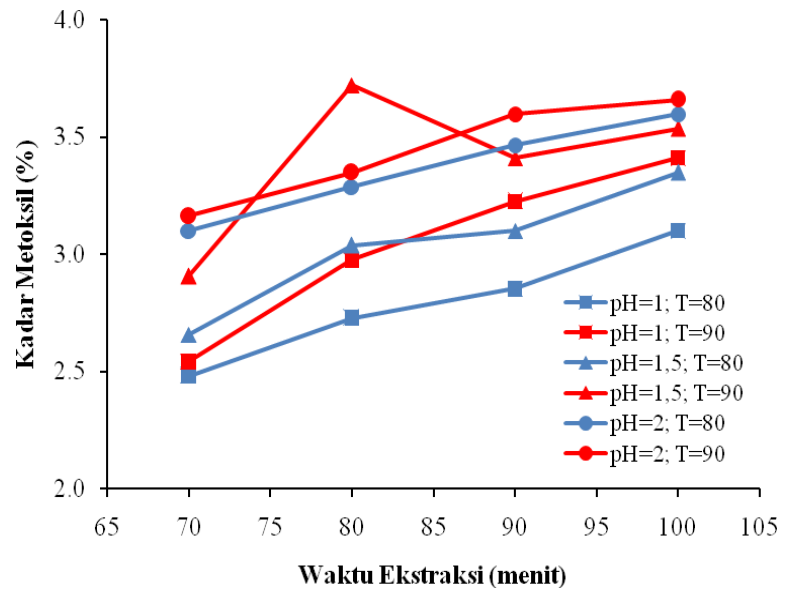

Gambar 7. Pengaruh pH dan waktu ekstraksi terhadap kadar metoksil pektin 


\section{Kesimpulan}

1. Rendemen yang terbaik pada waktu ekstraksi 80 menit pada suhu $90^{\circ} \mathrm{C}$ dan $\mathrm{pH} 1,5$ yaitu $52,1 \%$.

2. Kadar air pisang kepok tertinggi diperoleh sebesar $11,88 \%$ pada $\mathrm{pH} 1,5$ suhu $90^{\circ} \mathrm{C}$ dan waktu ekstraksi 80 menit.

3. Kadar abu pisang kepok terbaik diperoleh sebesar $0,98 \%$ pada $\mathrm{pH} 1,5$ suhu $90^{\circ} \mathrm{C}$ dan waktu ekstraksi 80 menit.

4. Kadar metoksil tertinggi diperoleh sebesar 3,72\% pada $\mathrm{pH} 1,5$ suhu $90^{\circ} \mathrm{C}$ dan waktu ekstraksi 80 menit.

5. Kualitas pektin yang dihasilkan dengan pelarut asam klorida $(\mathrm{HCl})$ ini telah memenuhi kriteria yang telah ditetapkan oleh IPPA (International Pectin Producers Association).

\section{Daftar Pustaka}

[1] Agus Budiyanto dan Yulianingsih, Pengaruh Suhu dan Waktu Ekstraksi terhadap Karakter Pektin dari Ampas Jeruk Siam (Citrus nobilis L), Jurnal Penelitian Pascapanen Pertanian 5(2), Hal 37-44, 2008.

[2] Badan Pusat Statistik Indonesia, Statistik Impor Indonesia, http://www.bps.go.id, Diakses: 24 Pebruari 2012, 2012.

[3] D. Constenla dan J.E. Lozano, Kinetic Model of Pektin Demethylation, Latin American Applied Research 33, Hal 91-96, 2003.

[4] F.G. Winarno dan M. Aman, Fisiologi Lepas Panen, Jakarta: Sastra Hudaya, 1986.

[5] Food Chemical Codex, Pektins, http://arjournals. annualreviews.org/doi/abs/10.1146/annure v.bi.20.070151.000435, 1996.

[6] G. Tchobanoglous, H. Theisen, dan S. Vigil, Integrated Solid Waste Management: Engineering Principles and Management Issues, New York: McGraw-Hill, Hal 3-22, 2003.

[7] Hasbullah, Teknologi Tepat Guna Agroindustri Kecil Sumatera Barat - Pektin Jeruk, Jakarta: Dewan Ilmu Pengetahuan, Teknologi dan Industri Sumatera Barat, 2001.

[8] International Pectin Producers Association, Pectin Commercial Production, http://www. google.com/IPPA.info.html, Diakses: 18 Pebruari 2012, 2003.

[9] Irwan Sofia, Produksi Pektinase dari Kulit Pisang dengan Jamur Aspergillus Niger, Jurusan Teknik Kimia, Institut Teknologi Bandung, 2008.

[10] J.R. Klavons, D. Bennet, dan S.H. Vanner, Physical/Chemical Nature Pectin
Associated with Commercial Orange Juice Cloud, Journal Food Science, 1995.

[11] N. Nurdjanah, dan S. Usmiati, Ekstraksi dan Karakterisasi Pektin dari Kulit Labu Kuning, Jurnal Penelitian Pascapanen Pertanian 3(1), Hal 13-23, 2006.

[12] Rona Joharni Nainggolan, Pengaruh pH dan Lama Ekstraksi terhadap Rendemen dan Mutu Pektin dari Kulit Pisang, Lab. Teknologi Hasil Pertanian USU, Medan, 1994.

[13] Salbilah, Ekstraksi Pektin dari Kulit Buah Kakao, Thesis Jurusan Farmasi Universitas Sumatera Utara, 1998.

[14] S. Hoejgaard, Pectin Chemistry, Funcionality, and Applications, http://www.cpkelco.com/ Ptalk/ptalk.htm, Diakses: 10 September 2012, 2004.

[15] S. Ranggana, Handbook of Analysis and Quality Control for Fruit and Vegetable Product, Second Edition, New Delhi: McGraw-Hill Publishing Company Limited, Hal 35, 2000. 